$\xi=-1$

\title{
Efficacy of Kumaun Himalayan Biota orientalis Endl. leaves extracts against pathogenic fungi
}

\author{
Savita Joshi, S. C. Sati, Parikshit Kumar* \\ Department of Botany, D.S.B. Campus, Kumaun University, Nainital-263001, UK-India \\ *Corresponding author E-mail:pk2461989@gmail.com
}

\begin{abstract}
An increasing demand for natural plant products has shifted the attention from synthetic to natural antifungal agents. This study was carried out to evaluate the antifungal activity of methanol, ethanol, chloroform, hexane and water extracts of Biota orientalis Endl. leaves, a Kumaun Himalayan gymnospermic plant. The antifungal potential of all extracts of $B$. orientalis were tested against seven different fungal strains (Alternaria alternata, Colletotrichum falcatum, Fusarium oxysporum, Pyricularia oryzae, Sclerotinia rolfsii, Sclerotinia sclerotiorum and Tilletia indica) using agar-well diffusion method. The ethanol extract was found most active against all the pathogens tested (Percent inhibition, 27-59\%) followed by hexane extract (Percent inhibition, 31-58\%) and methanol extract (27-57\%) while chloroform and aqueous extracts were found totally inactive against all the tested fungal strains, only chloroform extract showed inhibitory activity against $S$. rolfsii (\% inhibition, $58 \%$ ). The inhibitory activity of these extracts was found very effective as compared to Clotrimazol, standard antifungal agent that was used as positive control against tested fungal strains.
\end{abstract}

Keywords: Antifungal Activity; Biota orientalis; Kumaun Himalaya; Plant Extracts.

\section{Introduction}

Plants host many active substances, and are the basis of both ancient folk remedies and modern pharmacopeia (Sanjust et al. 2008, Pardo et al. 2010). Structural modification of antimicrobial drugs are an effective means of extending the lifespan of antifungal agents such as the azoles (Jeu et al. 2003), antiviral agents such as the non-nucleoside reverse transcriptase inhibitors (De Clercq 2001), and various antibacterial agents including $\beta$ lactams and quinolones (Poole 2001). Broad empirical screening of chemical entities for antimicrobial activity represents an alternative strategy for the development of novel drugs (Sati et al. 2015, Kumar et al. 2016). Natural products have been rich source of anti-infective agents, yielding, for example, the penicillins in 1940, the tetracyclines in 1948 and the glycopeptides in 1955 (Silver \& Bostian 1990).

Scientific efforts to discover new antifungal drugs are principally guided toward synthetic and natural products of plant origin (Marzouk et al. 2011). The extracts of many plants/herbs have been shown to exert biological activity in vitro or in vivo, justifying research on traditional medicine that focuses on the characterization of antifungal activity of these plants in India that have a diverse flora and a rich tradition for use of medicinal plants. Since plants produce a variety of compounds with antimicrobial properties, it is expected that screening programs for some under-represented targets, such as antifungal activity, may yield important compounds for antimicrobial remedies (Ahmad \& Beg 2001, Sati \& Joshi 2011).

Gymnosperms are almost a neglected group of plants in Himalayan region so as the antimicrobial activity of these plants have not been explored adequately so far (Sati \& Kumar 2015, Sati et al. 2015). From the rich biodiversity of the Kumaun Himalayan region of India, Biota orientalis Endl., commonly known as "morpankhi" or "Green Giant" is taken for this study. It is a fastest growing evergreen shrub or small bushy tree, 15-25 feet high and $4 \mathrm{~m}$ in diameter, much branched with dense cylindrical crown becoming thin and irregular at maturity, resinous and aromatic.

$B$. orientalis has different medicinal uses and pharmacological activities. It also has platelet activating factor (PAF) inhibitory effect related to pinusolid and pinusolidic acid (Yang \& Han 1998), neuroprotective activity related to $90 \%$ methanol fraction of $B$. orientalis against glutamate-induced neurotoxicity (Koo et al. 2002), cytotoxic activity by isolated deoxy podophyllotoxin (a lignane) from $B$. orientalis leaves against HeLa cells (Kosuge et al. 1985) and antimicrobial activity because of essential oils from twigs by hydrodistillation method and fruits by steam distillation method (Hassanzadeh et al. 2001, Bagci \& Digrak 1996). The present investigation is an attempt to evaluate the antifungal efficacy of leaves extracts of Kumaun Himalayan gymnospermous plants $B$. orientalis.

\section{Materials and methods}

\subsection{Collection of plant material}

Green leaves of Biota orientalis Endl. (Cupressaceae) were collected during the month of June from Nainital, Kumaun Himalaya, India and authenticated by the Department of Botany, Kumaun University, Nainital. A voucher specimen of plant species was submitted to the herbarium of Department of Botany.

\subsection{Preparation of the extract}

Leaves of the plant were thoroughly washed with distilled water and dried at the room temperature $\left(20 \pm 2^{\circ} \mathrm{C}\right)$. The dried material was powdered in an electric grinder. To prepare stock solution $50 \mathrm{~g}$ of this powder was placed in a $500 \mathrm{ml}$ conical flask mixed with $200 \mathrm{ml}$ of solvents $(\mathrm{w} / \mathrm{v}, 50 \mathrm{~g} / 200 \mathrm{ml})$. The mouth of flasks are 
tightly plugged with non-absorbent cotton and tightly wrapped with aluminium foil to prevent evaporation. Solvents used for extraction were methanol, ethanol, chloroform, and hexane. All flasks were shaken on a rotary incubator shaker at 190-220 rpm for $24 \mathrm{~h}$ at $37^{\circ} \mathrm{C}$. The mixtures were filtered through Whatman filter paper no.1 and the filtrate collected separately in a clean beaker. The extracts were evaporated, using steam bath to dryness at $30^{\circ} \mathrm{C}$. The dry extracts were kept in sterile sample bottles and stored in the refrigerator at $4^{\circ} \mathrm{C}$ for further use.

\subsection{Microorganisms used}

Seven fungal strains (Alternaria alternata, Colletotrichum falcatum, Fusarium oxysporum, Pyricularia oryzae, Sclerotinia rolfsii, Sclerotinia sclerotiorum and Tillatia indica) were obtained from Plant Pathology Department, Pantnagar University, Pantnagar, which were previously isolated from diseased plant materials.

\subsection{Antifungal screening}

The fungitoxic activity of different extracts was tested against seven fungal strains employing the Agar well technique of Grover and Moore (1962). Potato Dextrose Agar (Hi Media, $39 \mathrm{gm}$ of medium dissolved in $1000 \mathrm{ml}$ of distilled water) was used. The medium was autoclaved at $120^{\circ} \mathrm{C}$ for 30 minutes. $20 \mathrm{ml}$ of PDA media was poured into the $90 \mathrm{~mm}$ petri plates. After solidification of agar plates, the appropriate well was made on agar plate by using cork borer of size $7.0 \mathrm{~mm}$ and $200 \mu \mathrm{l}$ of the extract was added into each well. Mycelial disks ( $7 \mathrm{~mm}$ diam.) of actively growing colonies of tested fungal strains were cut from the periphery of the culture plates and aseptically placed $2.5 \mathrm{~cm}$ apart from the wells in the assay plates (90mm diam.). A standard antibiotic clotrimazole was used as positive control in the experiment. The tests were performed in triplicates and these plates were incubated at $25 \pm 2{ }^{\circ} \mathrm{C}$ for 4 to 5 days.

\subsection{Estimation of antifungal activity}

The antifungal activity of the extracts was analyzed by measuring the radial growth of the test fungi on $4^{\text {th }}$ day of incubation in 2 directions: $\mathrm{R}_{1}$ (radius in opposite direction) and $\mathrm{R}_{2}$ (radius in direction of the well filled with plant extract). Percent inhibition of radial growth was calculated as suggested by Fokkema (1973) and Perez (1990) and expressed as mean value with standard error of means (SEM).

$$
\text { Percent Inhibition }=\frac{R_{1-} R_{2}}{R_{1}} \times 100
$$

\section{Results}

In the present investigation different extracts of $B$. orientalis were screened for antifungal activity against seven pathogenic fungi. The results are summarized in table 1 . As shown in table 1 the hexane and chloroform extract showed low activity, while only ethanol and methanol extract had good antifungal activity. The aqueous extract was found totally inactive against all the pathogen tested. Hexane extract showed its activity in three tested organisms only, against A. alternata (percent inhibition, 58\%) followed by $S$. rolfsii (47\%) and P. oryzae (31\%).

Chloroform extract was found active only against $S$. rolfsii by showing 58\% inhibition. Ethanol extract showed a maximum inhibition 59\% against $S$. rolfsii, followed by $58 \%$ against $A$. solani. A low level inhibitory activity was also observed against $P$. oryzae (47\%), F. oxysporum (39\%), B. cineria $(37 \%)$ and C. falcatum (27\%). The extract was found inactive against $T$. indica (Table 1). For methanol extract, the highest percent inhibition was recorded against $S$. rolfsii (57\%). A moderate activity was observed against $P$. oryzae $(45 \%)$ followed by A. alternata (42\%), F. oxysporum (39\%), C. falcatum $(27 \%)$ and B. cineria $(26 \%)$. The results indicate that $S$. sclerotiorum is the most resistant fungal strain as no extract was able to inhibit it (Fig. 1). It is interesting to note that in some cases the plant extract showed better activity than the positive control "Clotrimazol" which is a standard antifungal agent (Fig. 1).

Table 1: Antifungal Activity of Different Extracts of B. orientalis

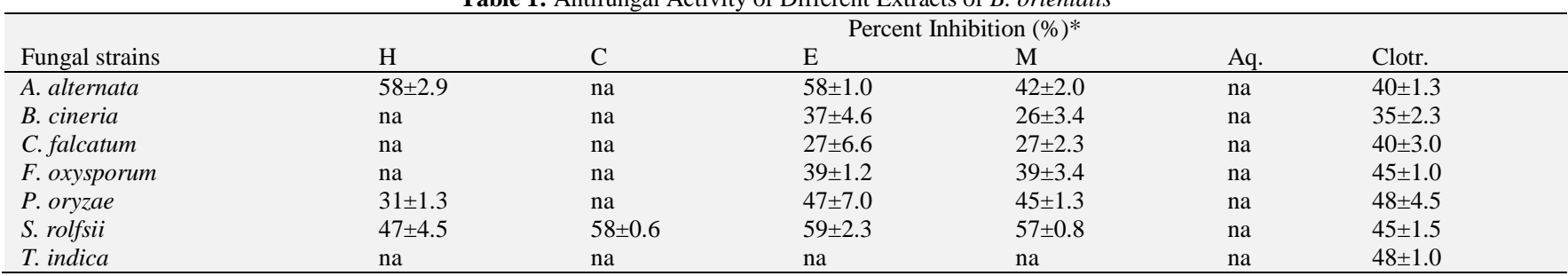

*All the values are mean \pm SEM of three determinations. H, C, E, M, Aq: Hexane, Chloroform, Ethanol, Methanol, Aqueous; Clotr.:Clotrimazol; na: not active

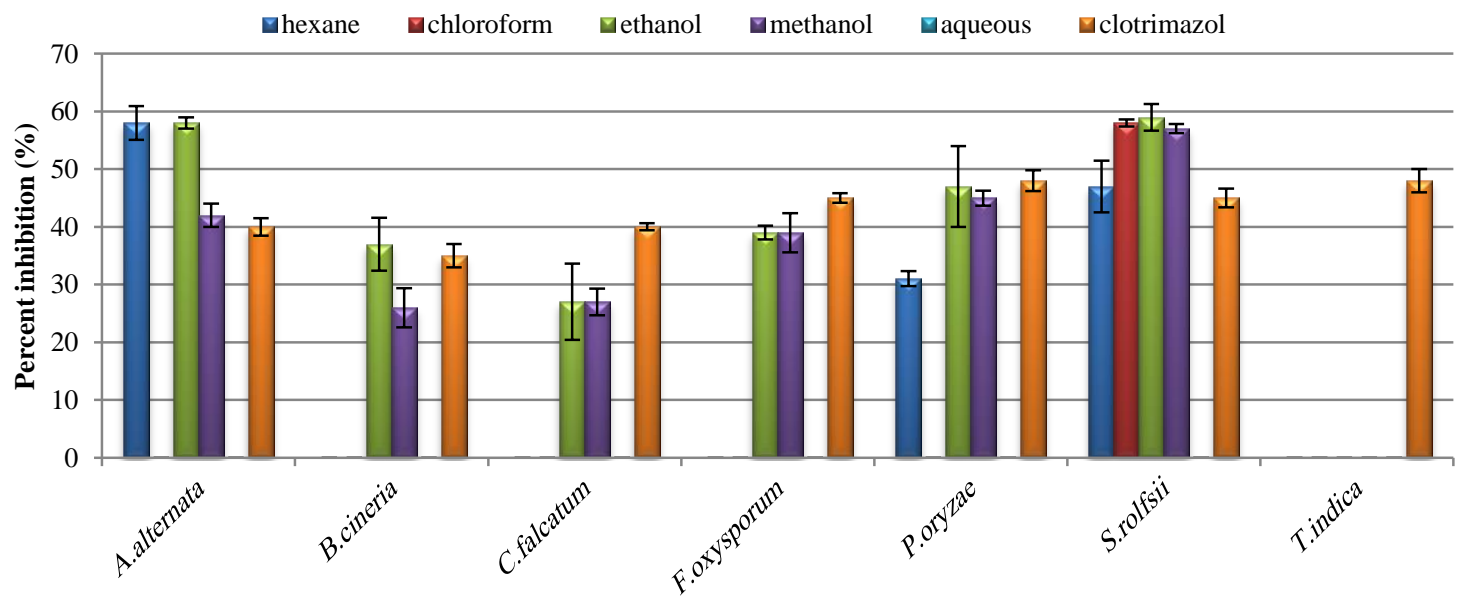

Fungal strains

Fig. 1: Antifungal Activity of B. orientalis against Some Fungal Strains. 


\section{Discussion}

Successful prediction of botanical compounds from plant material is largely dependent on the type of solvent used in the extraction procedure. Results of the antifungal assay carried out by agar well technique with aqueous and organic extracts of $B$. orientalis leaves were graphically represented in figure 1 . The results of the present study indicate that the plant $B$. orientalis assayed possess antifungal properties (Plate 1). This explains the use of this plant in folk medicine for treatment of various diseases whose symptoms might involve fungal infections and underline the importance of the ethnobotanical approach for the selection of plants in the discovery of new bioactive compounds.
As evident from the literature $B$. orientalis is well documented for its use for remedies of various ailments (Ezzat 2001, Nickavar et al. 2003, Naser et al. 2005, Guleria et al. 2008, Sati et al. 2014). In folk medicine $B$. orientalis has been used to treat bronchial catarrh, cystitis, urine carcinomas, amenorrhea and rheumatism (Peng\& Wang 2008). Biota plant ethanol fraction has been reported to produce protective potential against $\mathrm{CCl}_{4}$ induced liver damage in rats (Dubey \& Batra 2008). The antioxidant activity of aerial part of $B$. occidentalis ethanol fraction was evaluated by Dubey and Batra (2009). Essential oil of B. oriantalis has been widely used in steam bath. "THUJOIN" rich fraction separated from crude ethanolic extract of Biota had been reported to possess anticancer potential (Biswas et al. 2010).
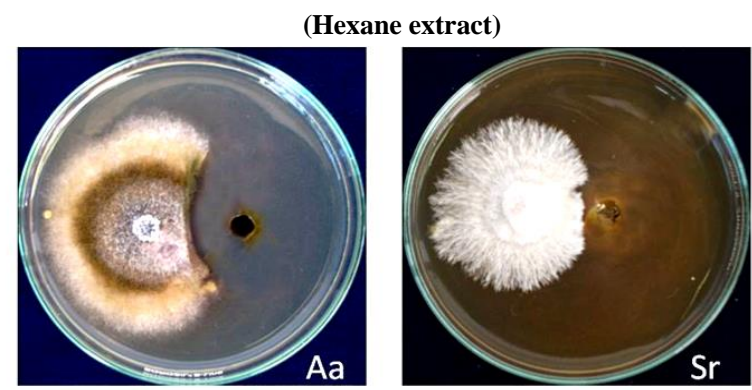

(Chloroform extract)

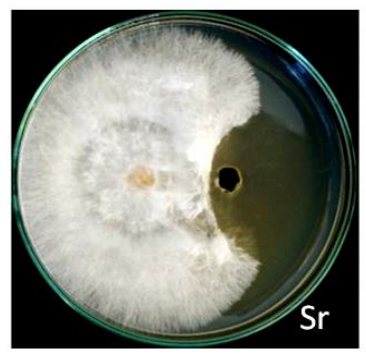

(Ethanol extract)
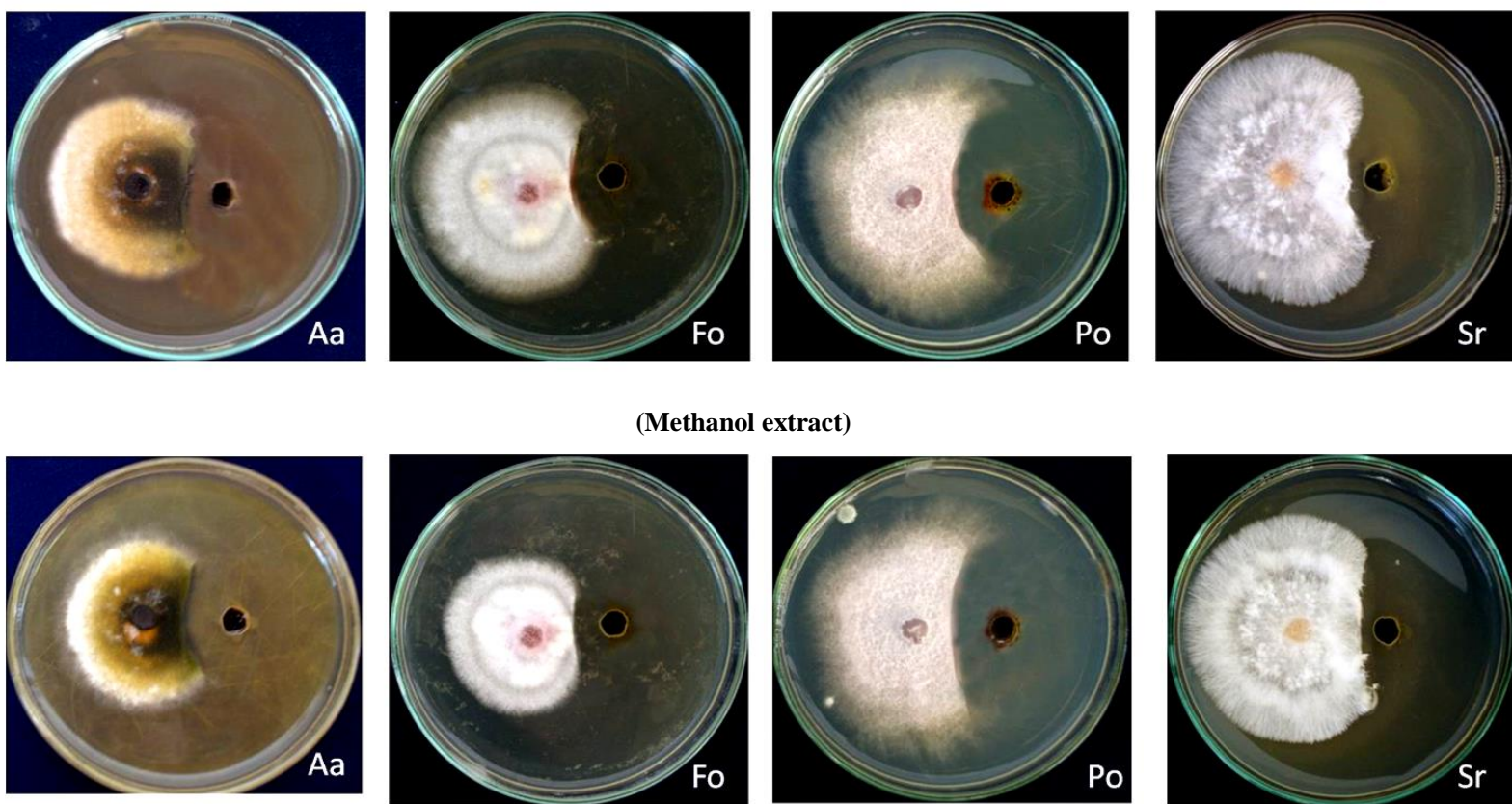

Fig.2: Antifungal Activity of Biota orientalis Extracts. Aa: A. alternata, Fo: F. oxysporum, Po: P. oryzae, Sr: S. rolfsii.

The pharcological effects of this plant has also been reported by some workers (Ezzat 2001, Nickavar et al. 2003, Naser et al. 2005, Guleria et al. 2008, Bissa et al. 2008, Bhan et al. 2011, Sati et al. 2014). Guleria et al. (2008) determined the chemical composition of this plant collected from north-western Himalaya and they found $\alpha$-pinene, $\alpha$-cedrol, caryophyllene, limonene, $\alpha$ - terpinolene and $\alpha$ - terpinyl acetate, active compound in leaf extract.
In the present investigation the antifungal activity of $B$. orientalis against 7 fungal strains showed a moderate activity by ethanol and methanol extracts were found effective against A. altarnata, $S$. rolfsii, and $P$. oryzae. No absolute inhibition was observed at $1000 \mu \mathrm{g} / \mathrm{ml}$ concentration for fungal pathogen. However it is remarkable to note that ethanol and methanol extracts were found 
more potential than the standard antifungal agent "Clotrimazol" used in present study (Figure 1).

Antifungal potential of $B$. orientalis was also evaluated by Guleria and Kumar (2006) and Guleria et al. (2008) but using their essential oils. In antifungal screening aqueous extract showed no activity against all the tested fungal strains (Table 1). This might be due to that substances which show activity are more soluble in organic solvents than aqueous medium and therefore, could not be presents in aqueous extract as suggested by Sati and Joshi (2010). Recently Srivastva et al. (2012), reviewed biological properties of $B$. orientalis and concluded that $B$. orientalis has the great potentiality against a number of health problem.

Relying upon the above, it is clear that the extracts of $B$. orientalis had very promising results against the tested fungal pathogenic strains in comparison to synthetic drug Clotrimazol. Thus the plant extracts are not only effective but also eco-friendly and requires more studies on this line.

\section{Acknowledgements}

We are thankful to University Grant Commission, New Delhi for financial support from UGC-BSR under SAP scheme. The authors wish to thank Department of Plant Pathology, G. B. Pant University of Agriculture and Technology, Pantnagar for providing fungal strains.

\section{References}

[1] Ahmad I \& Beg AZ (2001) Antimicrobial and phytochemica studies on 45 Indian medicinal plants against multi-drug resistant human pathogens. Journal of Ethnopharmacology 74, 113-123. http://dx.doi.org/10.1016/S0378-8741(00)00335-4.

[2] Bagci E \& Digrak M (1996) the antimicrobial activities of some forest trees essential oils. Turkish Journal of Biology 20, 191-198.

[3] Bhan M, Lal R, Dhimen A \& Nanda A (2011) Phyico-chemical and preliminary phytochemical and preliminary phytochemical investigation of Thuja occidentalis Linn. (Cupressaceae) dried leaves. International Research Journal of Pharmacy 2, 213-217.

[4] Bissa S, Bohra A \& Bohra A (2008) Antibacterial potential of three naked seeded (gymnosperm) plants. Natural Product Radiance 7, 420-425.

[5] Biswas R, Mandal SK, Dutta S, Bhattacharyya SS, Boujedaini N \& Khuda-Bukhsh AR (2011) Thujone-Rich Fraction of Thuja occidentalis Demonstrates Major Anti-Cancer Potentials: Evidences from In Vitro Studies on A375 Cells. Evidence-Based Complementary and Alternative Medicine 568148.

[6] De Clercq E (2001) New developments in anti-HIV chemotherapy. Farmaco 56, 3-12. http://dx.doi.org/10.1016/S0014827X(01)01007-2.

[7] Dubey SK \& Batra A (2008) Hepatoprotective activity from ethanol fraction of Thujao ccidentalis Linn. Asian Journal of $\mathrm{Re}-$ search in Chemistry 1, 32-35.

[8] Dubey SK \& Batra A (2009) Antioxidant activity of Thuja occidentalis Linn. Asian Journal of Pharmaceutical and Clinical Research 2, 73-76.

[9] Ezzat SM (2001) In vitro inhibition of Candida albicans growth by plant extracts and essential oils. World Journal of Microbiology and Biotechnology 17 , http://dx.doi.org/10.1023/A:1012934423019.

[10] Fokkema NJ (1973) the role of saprophytic fungi in antagonism against Drechslera sorokiniana (Helminthosporium sativum) on agar plates and on rye leaves with pollen. Physiological Plant Pathology 3, 195-205. http://dx.doi.org/10.1016/0048 4059(73)90082-9.

[11] Grover RK \& Moore JD (1962) Toximetric studies of fungicides against brown rot organism. Sclerotina fruticola. Phytopathology $52,876-880$

[12] Guleria S \& Kumar A (2006) Antifungal activity of some Himalayan medicinal plants using direct bioautography. Journal of Cell and Molecular Biology 5, 95-98

[13] Guleria S, Kumar A, \& Tiku AK (2008) Chemical Composition and Fungitoxic Activity of Essential Oil of Thuja orientalis L. Grown in the North-Western Himalaya. Z. Naturforsch 63c, 211-214.

[14] Hassanzadeh MK, Rahimizadeh M, FazlyBazzaz BS, Emami SA \& Asili J (2001) Chemical and antimicrobial studies of Platycladuso- rientalis essential oils. Pharmaceutical Biology 39, 388-390. http://dx.doi.org/10.1076/phbi.39.5.388.5894

[15] Jeu L, Piacenti FJ, Lyakhovetskiy AG \& Fung HB (2003) Voriconazole. Clinical Therapeutics 25, 1321-1381. http://dx.doi.org/10.1016/S0149-2918(03)80126-1.

[16] Koo KA, Sung SH \& Kim YC (2002) A new neuroprotective derivative from the leaves of Biota orientalis. Chemical Pharmaceutical Bulletin 50, 834-836. http://dx.doi.org/10.1248/cpb.50.834.

[17] Kosuge T, Ishida H \& Satoh T (1985) Studies on anti hemorrhagic substances in herbs classified as hemostatic in Chinese medicine, V. In Biota orientalis (L.) Endl. Chemical Pharmaceutical Bulletin 33, 206-209. http://dx.doi.org/10.1248/cpb.33.206.

[18] Kumar P, Joshi S, Sati SC \& Rai D (2016) A comparative evaluation of phytochemical and antibacterial properties of Ricinus communis Linn and Thevetia peruviana Schum. of Kumaun Himalaya Mintage Journal of Pharmaceutical and Medical Sciences 5, 13-19.

[19] Marzouk B, Marzouk Z, Mastouri M, Fenina N \& Aouni M (2011) Comparative evaluation of the antimicrobial activity of Citrulluscolocynthis immature fruit and seed organic extracts. African Journal of Biotechnology 10, 2130-2134.

[20] Naser B, Bodinet C, Tegtmlier M \& Lindequist U (2005) Thuja occidentalis (Arbor vitae): A review of its Pharmaceutical, pharmacological and Clinical properties. Evidence-Based Complementary and Alternative Medicine 2, 69-78. http://dx.doi.org/10.1093/ecam/neh065.

[21] Nickavar B, Amin G \& Parhami S (2003) Volatile constituents of the fruit and leaf oils of Thuja orientalis L. grown in Iran. Z. Naturforsch 58c, 171-172. http://dx.doi.org/10.1515/znc-2003-3404.

[22] Pardo-de-Santayana M, Pieroni A \& Puri RK (2010) Ethnobotany in the New Europe: people, health and wild plant resources. New York: Berghahn Books.

[23] Peng D \& Wang XQ (2008) reticulate evolution in Thuja inferred from multiple gene sequences: implications for the study of biogeographical disjunction between eastern Asia and North America. Molecular Phylogenetics and Evolution 47, 1190-1202. http://dx.doi.org/10.1016/j.ympev.2008.02.001.

[24] Perez C, Pauli M \& Bazerque P (1990) An antibiotic assay by the agar-well diffusion method. Acta Biologiaeet Medicine Experimentalis $15,113-115$.

[25] Poole K (2001) Overcoming antimicrobial resistance by targeting resistance mechanisms. Journal of Pharmacy and Pharmacology 53 , 283-294. http://dx.doi.org/10.1211/0022357011775514

[26] Sanjust E, Mocci G, Zucca P \& Rescigno A (2008) Mediterranean shrubs as potential antioxidant sources. Natural Product Research 22, 689-708. http://dx.doi.org/10.1080/14786410801997125.

[27] Sati SC, Joshi S \& Kumar P (2014) Antibacterial activity of Kumaun Himalayan Biota orientalis L. Leaf extracts. African Journal of Microbiology Research 8, 603-608. http://dx.doi.org/10.5897/AJMR2013.6467.

[28] Sati SC \& Joshi S (2010) Antimicrobial potential of leaf extracts of Juniperus communis L. from Kumaun Himalaya. African Journal of Microbiology Research 4, 1291-1294.

[29] Sati SC \& Joshi S (2011) Aspects of antifungal potential of ethnobotanically known medicinal plants. Research Journal of Medicinal Plants 5,377-391. http://dx.doi.org/10.3923/rjmp.2011.377.391.

[30] Sati SC, Kumar P \& Joshi S (2015) the bark extracts of Himalayan gymnosperm Picea smithiana (Wall.): A natural sources of antibacterial and antioxidant agent. International Journal of Pharmacy 106 445-452.

[31] Sati SC \& Kumar P (2015) Assessment of Himalayan juniper, Juniperus squamata buch- ham ex d. don for phytochemical screening and antimicrobial potential against some infection causing pathogens. World Journal of Pharmaceutical Research 4 998-1011.

[32] Silver L \& Bostian K (1990) Screening of natural products for antimicrobial agents. European Journal of Clinical Microbiology and Infectious Diseases 9 9, 455-461. http://dx.doi.org/10.1007/BF01964283.

[33] Srivastava P, Kumar P, Sing, DK \& Singh VK (2012) Biological Properties of Thuja orientalis Linn. Advances in Life Sciences 2. 17-20. http://dx.doi.org/10.5923/j.als.20120202.04.

[34] Yang HO \& Han BH (1998) Pinusolidic acid. A platelet activating factor inhibitor from Biota orientalis. Planta Medica 64, 73-74. http://dx.doi.org/10.1055/s-2006-957371. 